\title{
Encontros Globais e Confrontos Culturais: 0 Pentecostalismo Brasileiro à Conquista da Europa
}

\author{
Ari Pedro Oro ${ }^{1}$ \\ Daniel Alves ${ }^{2}$
}

${ }^{1}$ Universidade Federal do Rio Grande do Sul (UFRGS), Porto Alegre, RS, Brasil. E-mail de contato: arioro@uol.com.br

${ }^{2}$ Universidade Federal de Goiás (UFG), Catalão, GO, Brasil. E-mail:

danalves1978@yahoo.com.br

\section{INTRODUÇÃO}

$\mathrm{O}$

processo histórico de encurtamento das dimensões do espaço e do tempo promovido pelas novas tecnologias de transporte e comunicação, a que nos referimos quando falamos genericamente de "globalização", levou a desenvolvimentos que requerem dois tipos de atenção intelectiva. O primeiro, de cunho teórico, envolve a criação de um aparato conceitual que capacite os analistas a identificar e interpretar movimentos globais. O segundo, de cunho empírico, consiste em rastrear fluxos de pessoas, informações e recursos que passam certas vezes ao largo de esferas institucionais do Estado ou de instituições centralizadoras. As interpretações acerca das relações entre religião e globalização ganharam, nas últimas décadas, espaço no campo das ciências sociais, e poderiam se beneficiar do emprego destas duas formas de atenção. Neste artigo analisamos fluxos de missionários brasileiros de Porto Alegre em direção à Europa. Seguindo "imagens da ordem global” (Robertson, 1996) construídas especialmente no mundo evangélico pentecostal, podemos estabelecer a versão dos atores para esse fluxo, que, em grande medida, está calcada na ideia de "missão invertida".

A “missão invertida" (Freston, 2004, 2010), "evangelização ao contrário" (Mary, 2008), ou "evangelização de retorno" (Trombetta, 2013) constitui um importante objeto de interesse das ciências sociais que se

DADOS - Revista de Ciências Sociais, Rio de Janeiro, vol. 58, n- 4, 2015, pp. 951 a 980.

http://dx.doi.org/10.1590/00115258201563 
ocupam da religião na atualidade. Isto porque se constata na vasta literatura sobre o tema a convergência de uma política de recristianização da Europa tanto por parte de igrejas pentecostais latino-americanas quanto africanas (ver os dossiês organizados por Capone, 2004; Cingolani e Gusman, 2013; Oro et al., 2009; e também em livros publicados por Trombetta, 2013; Rocha e Vásquez, 2013; Argyriadis et al., 2012; Oro, Steil e Rickli, 2012; Pace e Butticci, 2010; Währish-Oblau, 2008; Spindler e Lenoble-Bart, 2000; Bastian, Champion e Rousselet, 2001). A "missão invertida" pode assim ser definida: "aqueles que um dia foram objeto de missão, catequisados nas colônias, invertem o fluxo histórico, enviando missionários para as metrópoles, com a consigna de converter a seus cidadãos" (Carranza e Mariz, 2013:29)1.

Paul Freston (2010:155) chama a atenção para o fato de que a "missão invertida" não consiste somente numa inversão geográfica, sul-norte. Ela é também social, no sentido de que provém "de baixo", invertendo as posições no mapa mundial, assemelhando-se à expansão do Cristianismo dos primeiros tempos. Seria, como destacam Ruiz e Michel, "uma forma de revanche histórica do colonizado sobre o colonizador" (2012:135, tradução livre).

Este artigo versa sobre quatro igrejas pentecostais de Porto Alegre que colocam em prática a política da "reconquista espiritual da Europa". São elas: Igreja Batista Brasa, Igreja Assembleia de Deus, Igreja Maanaim e Igreja/Ministério Encontros de Fé2. Os países contemplados por estas igrejas são, sobretudo, Reino Unido, Portugal e Itália. Dois tópicos serão privilegiados na análise: em primeiro lugar, as estratégias postas em prática pelas igrejas para implementar a missão na Europa e os sentidos atribuídos a esta iniciativa; em segundo, as tensões enfrentadas pelos missionários brasileiros em suas experiências transnacionais na Europa. Ou seja, mostramos que paralelamente ou juntamente à comprovada e histórica capacidade pentecostal de adaptar-se às culturas locais ocorrem também tensões e embates que podem provocar desentendimentos e até mesmo conflitos.

Esclarecemos de saída que as quatro igrejas mencionadas operam na Europa adotando um modelo de atuação diferente daquele executado pelas grandes igrejas neopentecostais brasileiras implantadas no exterior, como Deus é Amor, Renascer em Cristo, Mundial do Poder de Deus, Internacional da Graça de Deus e, sobretudo, a Universal do Reino de Deus. Estas se internacionalizam abrindo "filiais" no exterior 
com o objetivo de conquistar fiéis no competitivo mercado religioso local. Para tanto, na medida do possível recorrem às mídias e a outras estratégias de marketing para divulgarem os seus serviços e atraírem novos consumidores religiosos. Atuam como "empresas multinacionais de salvação" exclusivas, que competem entre si e com as igrejas locais, não mantendo com elas nenhuma relação ecumênica e obedecendo as orientações e diretrizes que emanam das "matrizes" que se encontram no Brasil. Já as igrejas sobre as quais nos ocupamos neste artigo operam transnacionalmente obedecendo a outra lógica: firmam parcerias com igrejas no exterior, onde predomina o associativismo, uma espécie de contrato interinstitucional que geralmente se beneficia de alianças nutridas por afinidades interpessoais ${ }^{3}$, o que não significa, como veremos, que as relações entre elas sejam harmônicas e pacíficas. Iniciamos, porém, tecendo algumas considerações sobre o conceito de transnacionalização, que privilegiamos neste estudo.

\section{TRANSNACIONALIZAÇÃO E RELIGIÃO: UMA DISCUSSÃO CONCEITUAL}

Os fenômenos sociais caracterizados por atravessamentos de pessoas, informações ou recursos entre países foram reconhecidos, ao longo dos últimos anos, através de um conjunto de conceitos que demandam ser relacionados de alguma maneira. Passamos a tecer considerações que visam situar nosso ponto de vista acerca desse campo conceitual ${ }^{4}$.

Globalização e transnacionalização não são, a nosso ver, conceitos excludentes. Possuem, antes, uma relação hierárquica. As características essenciais do fenômeno (aquilo que Robertson chamava de "compressão do espaço e do tempo" promovida pelas novas tecnologias de informação) abarcam todos os aspectos, inclusive o que nominamos como "transnacionais". A globalização, que entendemos como um processo civilizatório contemporâneo, oferece um horizonte de sentido, ou paisagem, dentro do qual os movimentos "internacionais", "transnacionais", "diaspóricos" ou "globais" fazem sentido para os atores. Resulta disso que "globalização", como processo, envolve todos os demais conceitos.

"Internacionalização" refere-se a movimentos de organizações societárias que promovem produções de bens materiais ou imateriais irradiados e replicados a partir de um centro para os lugares de destino. Assim, as grandes corporações se internacionalizam baseados em lugares diferentes do globo: eles reterritorializam uma referência organi- 
zacional, produtiva ou cultural, central. Os movimentos ideais da internacionalização são os das grandes corporações do Norte ou aqueles dos Estados-nação, quando estabelecem embaixadas em países estrangeiros. O "supranacionalismo" de organismos como a Organização das Nações Unidas (ONU) não é nada mais do que uma variação deste tema.

"Diáspora" concerne, como tipo ideal, movimentos especialmente migratórios ou culturais nos quais uma comunidade étnica se integra longe de seu lugar de referência. A diferença da "internacionalização" reside exatamente no aspecto comunitário.

"Globalização" é tomada por muitos autores não só como processo, mas também como fato objetivo da realidade. Aqui delimitamos a abordagem sociológica calcada nas ideias de desenvolvimento, hegemonia e desigualdade. Os autores são famosos (o mais emblemático seria Samuel Huntington) e o que os caracteriza ficou conhecido como "nacionalismo metodológico". Assim como as sociologias dependem da análise de instituições, as análises calcadas no nacionalismo metodológico precisam de unidades de análise e comparação, que são países ou culturas (não raro tomados como sinônimos), ainda que os fluxos guardem referências de múltiplos lugares. Os fluxos observados, por isso, são sempre de escala macro, com ênfase nos processos de homogeneização cultural. Aspectos sutis dos encontros culturais e a cristalização dos imaginários mútuos sobre as culturas frequentemente são desconsiderados em face das macrotendências dos alinhamentos de poder em escalas mais amplas. A objetificação do conceito tende a tornar a "globalização" um processo histórico no qual uma "cultura global" dissemina-se como uma nova forma de senso comum ${ }^{5}$.

"Transnacionalização" diz respeito a processos de atravessamento de organizações societárias com respeito a fins, produções ou culturas caracterizados pela dispersão e adaptação ao local receptor. "Transnacionalização" afasta-se da visão objetificada do conceito de globalização por dois motivos. Um deles se refere ao reconhecimento de fluxos anti-hegemônicos obliterados pela ênfase nas macrotendências; o outro ao papel dos sujeitos na análise, muito mais ativo. Devido a esses fatores, os trabalhos sobre transnacionalização enfatizam menos fluxos norte-sul do que aqueles centrados no conceito objetificado de "globalização". Ulf Hannerz (1996), por exemplo, propôs o conceito de transnacionalização ao invés de globalização ${ }^{6}$ para enfatizar o fluxo 
de indivíduos e de grupos, e não somente de empresas, na arena mundial. Alejandro Frigerio e outros estudiosos ampliaram o conceito. De fato, o antropólogo argentino considera a globalização como sendo uma "transnacionalização pelo alto", posto que ela "descreve os esforços das corporações multinacionais, da mídia e de outras elites sociais poderosas para estabelecer dominação política, econômica e social no mundo" (Frigerio, 2013:19). Já os fluxos religiosos transnacionais constituem uma "transnacionalização por baixo", a qual, no dizer de Smith e Guarnizo, faz referência a "esforços conscientes e bem-sucedidos da parte de pessoas comuns para escapar da dominação 'desde acima' do capital e do Estado" (1998:5; tradução livre; ênfase do original). Por isso mesmo, Capone e Mary (2012:30; tradução livre), destacam a dimensão política da transnacionalização. Ela constitui um "'espaço político contra-hegemônico' que desloca o jogo das discriminações impostas desde cima", constituindo um complemento ou o reverso da mundialização econômica e tecnológica.

Frigerio sublinha que a "transnacionalização por baixo" pode ocorrer de duas maneiras principais: (a) enquanto "circulação ou fluxo de pessoas e/ou bens distintos de um país para outro, ou então (b) como o estabelecimento de um campo social formado por uma variedade de conexões que transcendem as fronteiras nacionais" (Frigerio, 2013:17).

Em seu estudo sobre a expansão das religiões afro-brasileiras, sobretudo do Rio Grande do Sul para os países do Prata, Frigerio mostrou como ambas as perspectivas teóricas se complementam, uma vez que a circulação das crenças e práticas afro-religiosas entre Brasil, Argentina e Uruguai ocorreu mediante o fluxo social multidirecional não migratório (primeira perspectiva), formando, mesmo assim, um campo social transnacional afro-religioso, apoiado, em grande medida, na noção de linhagens religiosas, baseadas em redes de relacionamento (segunda perspectiva).

Como veremos neste estudo, semelhante situação que implica na dupla possibilidade de transnacionalização religiosa parece ser também recorrente no campo pentecostal que abraça a política da missão invertida para a Europa.

Importa reter, do que precede, que a transnacionalização possui duas características principais. Em primeiro lugar, como sustenta Alves (2011:32), ela se refere a fluxos de pessoas que se juntam em "redes de relações (...) com níveis de institucionalização variáveis, atravessando 
espaços societários diferentes"7; e, em segundo, como defende Hannerz (1996), ela não está contida "dentro de um Estado", não possui uma base fixa nos Estados nacionais. Ou então, como frisaram Badie e Smouts $(1995)^{8}$, a transnacionalização mantém fraca (ou nenhuma) relação com os aparelhos de Estado, embora isto dependa da situação legal e conjuntural que vigora em cada país.

Essas características, como veremos, também estiveram presentes no acompanhamento que fizemos das quatro igrejas pentecostais radicadas em Porto Alegre que efetuam a "missão invertida" para a Europa.

\section{AS IGREJAS E SEUS FLUXOS TRANSNACIONAIS NA EUROPA}

As igrejas e pastores que passamos a examinar a seguir possuem um elemento em comum: alcançam a Europa através de parcerias celebradas com igrejas e agentes religiosos europeus. É através de "alianças estratégicas" (Castells, 2000) que eles desencadeiam a transnacionalização religiosa para a Europa. Um dos precursores deste modelo de parcerias e de construção de redes sociais no interior do campo evangélico-pentecostal é o renomado evangelista argentino Carlos Annacondia", que afirma: "Antes tudo estava centralizado nas instituições. Agora, a ênfase é posta nas redes. É preciso olhar as redes. A Igreja do Espírito Santo é composta de indivíduos que se associam em redes" ${ }^{\prime \prime}$.

Annacondia, além de protagonizar uma importante transição do pentecostalismo nos anos 1980 na Argentina (Wynarczk, 1993), foi um dos primeiros, nas redes de líderes pentecostais que estudamos, a estender sua atuação para além das fronteiras nacionais de seu país e da América Latina. A forma de construção de reputação através de convites e parcerias baseadas numa compreensão religiosa do sentido das redes difundiu-se a partir de sua atuação. Examinemos de agora em diante exemplos da constituição de redes transnacionais em direção à Europa, abordando as formas de sustento dos agentes envolvidos, a comunicação com as sedes e a relação com as agências de controle migratório nacionais.

\section{Convites e Parcerias}

O pastor Luiz Bazerque, responsável pela área de missões da Igreja Batista Brasa ${ }^{11}$ de Porto Alegre, diz ${ }^{12}$ que o trabalho voltado para a Europa "veio para nós no final dos anos 1990 como um convite, um pedido 
de socorro, de alguns pastores da Inglaterra e de Portugal". Foi um período, acrescenta, em que, especialmente no Reino Unido, as igrejas estavam fechando as portas, pois o número de fiéis estava encolhendo e os prédios históricos e centenários estavam sendo ocupados para outras finalidades, como museus, bibliotecas, lojas etc. Veio também de Portugal "um convite, um pedido de ajuda. Mas eles não tinham como começar. Então nós fundamos uma igreja em Portugal", inicialmente em Espinho e, mais tarde, na cidade do Porto.

Também na Assembleia de Deus a prática missionária na Europa iniciou com um convite. Segundo o pastor Joel Lucas ${ }^{13}$, secretário de missões desta igreja em Porto Alegre, "precisa realmente primeiro vir de lá um convite. Nunca a gente vai assim pra fazer um trabalho independente; a gente vai pra trabalhar junto com as igrejas de lá".

A ida do pastor Josué Dilermando, da Igreja Maanaim ${ }^{14}$, ao País de Gales, em 2009, também se deveu a um convite recebido de uma pastora brasileira, casada com um galês. Igualmente o pastor Edilson Avila, da mesma igreja, foi a Roma a convite do pastor italiano Ugo Sottile, que esteve em Porto Alegre em janeiro de $2011^{15}$.

A recente ida do pastor Dilermando para Bucareste se deve a uma parceria pessoal firmada com o pastor romeno Bolozani Mihai. Dilermando conta que o conheceu aqui no Brasil e que este "me contou da necessidade do país" e "me convidou para ir ajudar ele"16. As tratativas ocorreram via internet e em setembro de 2013 Dilermando partiu para Bucareste, para pregar na Igreja Dumnezeu si dragoste ${ }^{17}$. No último dia de sua estada na Romênia, em 22 de setembro de 2013, postou em seu Facebook o seguinte agradecimento: "Agradecemos o convite do pastor Bolozani Mihai e pelo acolhimento da sua esposa Irma Milena Mihai e também a igreja Dumnezeu si dragoste".

Segundo Dilermando ${ }^{18}$, esta é a fórmula do seu trabalho missionário na Europa: encontrar igrejas e pastores parceiros para trabalhar com eles. Formar uma rede com igrejas e pastores. "Não é chegar lá [Europa] e abrir igrejas; não é fazer um império, como outras igrejas fazem". Enfim, Elias Figueiró, do Ministério Encontros de Fé, também desta$\mathrm{Ca}^{19}$, referindo-se às suas viagens transnacionais: “(...) sempre contatos, convites, trocas".

Portanto, as parcerias firmadas entre igrejas de Porto Alegre e de alguns países europeus resultam de convites provenientes do Velho 
Continente. Os convites conduzem à construção de parcerias, institucionais e/ou pessoais, as quais se constituem, como assinalou Joanildo Burity (2006) em seu estudo sobre as parcerias entre organizações da sociedade civil e agências governamentais, em "recurso estratégico" para alcançarem seus objetivos, que, no caso das igrejas brasileiras referidas, como veremos, consiste em "recristianizar a Europa" (Oro e Mottier, 2012).

\section{O Sustento dos Missionários na Europa}

Na Igreja Batista Brasa, durante os primeiros anos das parcerias, o sustento dos missionários brasileiros na Europa ficou a cargo das igrejas europeias. Porém, como afirma o pastor Bazerque20, nos últimos anos, com a crise econômica na Europa, "algumas igrejas [no caso, do Reino Unido], que bancavam todo o salário do pastor, hoje elas não conseguem fazer mais. Hoje nós participamos disso". Especialmente as "igrejas menores não conseguem dar todo o salário e uma casa. Por isso, parte do sustento a gente garante".

O mesmo ocorreu com os pastores da Assembleia de Deus. No início do seu trabalho missionário na Europa, foram acolhidos e apoiados, também financeiramente, pelas igrejas locais. Porém, assim como ocorreu com a Igreja Batista Brasa, com o passar do tempo o sustento dos missionários tornou-se praticamente uma tarefa das igrejas brasileiras. Neste sentido, segundo o pastor Joel Lucas, é comum acontecer um "consórcio de igrejas" brasileiras para sustentar os pastores em missão, mesmo os que estão atuando na Europa.

Também o pastor Edilson e família foram inicialmente acolhidos e apoiados pela Igreja Assembleia de Deus de Roma, mas, passados alguns meses, tiveram que prover o seu próprio sustento. Para tanto, Edilson e sua esposa realizam hoje diferentes serviços temporários. Além disso, para completar a receita mensal da família, a Igreja Maanaim de Porto Alegre envia quase que mensalmente dinheiro para Roma.

A recente viagem do pastor Dilermando para a Romênia e para a Itália foi toda ela custeada pela sua igreja brasileira. Uma semana antes da sua partida, em 11 de setembro de 2013, o pastor anunciou em sua página do Facebook que iria "para a Europa em mais uma viagem missionária" e solicitou ajuda financeira, "uma oferta de amor". Para tanto, 
informou os seus números de telefone pessoais e o número de sua conta no banco Itaú.

O renomado músico evangélico radicado em Porto Alegre Asaph Borba $^{21}$, que circula bastante no meio evangélico europeu, frisa ${ }^{22}$ que hoje em dia, apesar das parcerias que as igrejas europeias mantêm com as igrejas brasileiras, são estas últimas que sustentam seus missionários no exterior. Para ele, "quem envia missionários (mesmo para a Europa) sustenta daqui, com dinheiro brasileiro".

Deduz-se que o envio e a manutenção de missionários na Europa implicam em custos altos por parte das igrejas locais que, mesmo assim, por razões que veremos mais adiante, tendem a não desistir do projeto de "recristianização da Europa". Cabe agora examinar como interagem, se comunicam, os pastores locais com os seus parceiros europeus, ou com os missionários que se encontram em cidades europeias.

\section{As Parcerias e a Internet}

Em seus estudos sobre a transnacionalização afro-religiosa no Cone Sul, Frigerio (2013:47) sublinha que "é um truísmo (dizer) que a internet oferece uma arena privilegiada para o estabelecimento de redes transnacionais". O mesmo poder-se-ia afirmar relativamente ao campo evangélico. Hoje em dia, a maioria das igrejas evangélicas e pentecostais possui sua própria página na web, com plataformas bem-feitas, diga-se de passagem, além de explorarem as possibilidades de relacionamentos via internet como o Facebook, Skype, Twitter e MSN (até $2009)^{23}$. A presença na web constitui uma importante vitrine de divulgação dos trabalhos realizados pelas igrejas, permitindo, assim, transcender o nacional e aceder ao transnacional.

Evidentemente a internet é útil tanto para estabelecer e manter contatos transnacionais entre as igrejas parceiras quanto para manter a comunicação transnacional entre os membros das igrejas que se encontram no exterior. De fato, os depoimentos dão conta de que os líderes das igrejas locais se comunicam constantemente com membros dirigentes de igrejas europeias e com os missionários em atuação. Neste sentido, o responsável das missões da Igreja Batista Brasa informa que mantém contatos diários com os seus pastores no exterior. Além disso, ao menos uma vez por ano um responsável de missões da igreja faz uma viagem para verificar in loco o trabalho dos seus missionários. Também o pastor Dilermando afirma que conversa diariamente, via 
Skype ou Facebook, com Edilson Avila, que está em Roma. Dilermando enfatiza que diante de Deus se sente responsável por Avila e sua família. Por isso, acrescenta: “(...) a gente tem que estar conectado; eu daqui tenho que estar fortalecendo com palavras de ânimo, encorajando ele, que está lá no campo de batalha"24.

A internet constitui, portanto, uma importante ferramenta para assegurar as relações sociais e manter as redes de relacionamento entre os agentes religiosos e as igrejas transnacionais. Assim, neste contexto de uma transnacionalização religiosa que ocorre sobretudo mediante intercâmbios e circulação de atores sociais (agentes religiosos), a internet torna-se uma importante mediação para a constituição de um "campo social transnacional" (Capone, 2010). Isto significa, em outras palavras, que se repete no contexto da transnacionalização evangélicopentecostal uma certa recorrência da dupla possibilidade de transnacionalização que Frigerio (1993) havia constatado no Mercosul relativamente à transnacionalização afro-religiosa, como foi assinalado anteriormente, ou seja, uma transnacionalização que envolve deslocamentos e circulação de atores sociais que se organizam em redes sociais formando um campo social transnacional.

Vejamos agora que tipo de relações mantêm os atores sociais implicados no processo de transnacionalização religiosa com os aparelhos de Estado.

\section{A Transnacionalização e os Controles Estatais de Migração}

A segunda característica da transnacionalização consiste na relação com as instâncias estatais de controle migratório que vai da aproximação estratégica à evitação total. É o que também ocorre com as quatro igrejas referidas, as quais recorrem às instâncias oficiais somente para satisfazerem as exigências legais de ingresso e a permanência dos seus missionários nos países em missão: passaportes e vistos, caso desejem permanecer por mais tempo do que o permitido para turistas. Assim, a maioria dos pastores desembarcam na Europa como turistas ou como trabalhadores. "Dificilmente vão para a Europa como religiosos. Vão com outra finalidade: alguns vão como turistas, vão como trabalhadores, vão renovando o visto", esclarece o músico Asaph Borba. A consequência disto, segundo o mesmo informante, é que nem todos os religiosos que atuam na Europa estão documentados. Diz ele: "Eu conheço pastor ilegal, conheço pastor que consegue o documento 
como religioso e conheço gente que vai como trabalhador, consegue um visto de trabalho, tem uma profissão".

A Igreja Batista Brasa, no início da sua atividade na Inglaterra, por intermédio do pastor Marcelo Guimarães, encontrou no estudo de inglês para os pastores recém-chegados do Brasil uma alternativa para obter visto de permanência de um ano. Assim, durante vários anos a própria igreja de Bognor Regis assegurou a escola de inglês para os missionários brasileiros, contribuindo, desta forma, para facilitar a sua permanência legalizada. Nos últimos anos, porém, devido às mudanças na legislação local, esta alternativa já não existe mais. Por isso mesmo, a situação do visto ficou bastante complicada.

O ingresso dos missionários brasileiros da Assembleia de Deus na Europa geralmente se dá como turistas. Procuram, então, ligar-se a uma igreja local, a partir da qual iniciam um processo de tramitação de documentos visando a obtenção de um visto de permanência temporária. Também o pastor Dilermando viaja como turista. Por sua vez, os pastores Edilson Avila e sua esposa Ana, depois de três anos de permanência em Roma, conseguiram visto de permanência temporária ${ }^{25}$. "Foi um milagre de Deus", afirmou pastor Dilermando ${ }^{26}$.

Importa assinalar aqui que as distâncias relativas mantidas pelas igrejas transnacionais em relação às instâncias estatais não significa que as mesmas desconsiderem as identidades nacionais. Ao contrário, a ideia de nação e a reivindicação da nacionalidade integram os fluxos transnacionais, fato verificado não somente na explicitação constante dos vínculos nacionais das igrejas e dos agentes religiosos, mas também, e sobretudo, na ostentação, sempre que possível, de bandeiras nacionais enquanto símbolos representativos das nações nos recintos religiosos. Assim, o recurso às bandeiras por parte das igrejas pentecostais e neopentecostais brasileiras transnacionais revela não apenas a articulação entre o "nacional" e o "transnacional", mas também a afirmação das nacionalidades (Oro, 2010).

Vamos agora nos ater ao tópico concernente à motivação das quatro igrejas referidas para fechar parcerias com igrejas e atores religiosos europeus e implementar o processo de transnacionalização, a saber: o seu desejo de "recristianizar a Europa" ou "reconquistar espiritualmente a Europa". 


\section{A "RECONQUISTA ESPIRITUAL DA EUROPA"}

Predomina nas quatro igrejas referidas, mas não somente nelas, um mesmo discurso sobre a religião na Europa, sobretudo nos países católicos: a modernidade ${ }^{27}$ que ali vigora fez com que eles se desviassem da verdadeira fé em Jesus, posto que seus habitantes seriam hoje demasiadamente "frios" do ponto de vista espiritual e apegados ao materialismo e hedonismo, com muita ênfase no individualismo. Segundo o pastor Josué Dilermando: "O problema da Europa é a modernidade, o pensamento moderno e a secularização, o racionalismo e o individualismo. Este pensamento não agrada a Deus" ${ }^{\prime 28}$. Já o pastor Joel Lucas sustenta que "a chama se apagou na Europa", e que hoje restam somente as cinzas dos avivamentos de outrora.

Consideram os líderes religiosos entrevistados que não podem permanecer passivos diante dessa situação que vigora na Europa. Ao contrário, como sintetiza o pastor Dilermando, faz-se necessário encetar esforços para "reconquistar espiritualmente a Europa". É tão forte esta pretensão que o pastor chega a afirmar: "minha preocupação hoje não é evangelizar o Brasil; hoje minha preocupação é evangelizar a Europa. Por isso, estou interessado na formação de pessoas que tenham amor para a missão, para enviar eles para a Europa".

Por seu turno, o pastor Luiz Bazerque, da Igreja Batista Brasa, considera que os europeus foram os pais que trouxeram o evangelho para os filhos do sul, mas que agora "está na hora de nós, filhos, voltarmos aos pais, auxiliarmos os pais, fortalecermos os pais para juntos agora, filhos e pais, completarmos essa onda". Trata-se, segundo ele, de uma missão que parte dos "confins do mundo". "Tem pastores que dizem que estamos vivendo Atos 1:829, algo reverso hoje. Os confins do mundo é que estão fazendo essa mesma rota, voltando para a Europa".

Outro pastor da Assembleia de Deus, Paulo Locatelli, que já esteve pregando em vários países da Europa, assevera que o Brasil possui uma dívida em relação à Europa ${ }^{30}$. Isto porque os europeus trouxeram a mensagem religiosa que aqui foi guardada e cresceu. Para ele, a missão invertida é a devolução, o retorno do que "eles nos deram, porque hoje eles vivem o que talvez uma vez a gente viveu aqui, no passado. Estamos pagando uma dívida".

Os pastores entrevistados, por outro lado, confessaram que a maior parte dos fiéis dos pastores brasileiros na Europa não são europeus, e 
sim brasileiros, latinos e africanos ${ }^{31}$. Da mesma forma, nenhum dos entrevistados referiu convictamente a conversão de europeus como resultado da ação religiosa dos seus missionários ${ }^{32}$. Os obstáculos mais importantes para a conversão de europeus, na avaliação dos agentes religiosos entrevistados, são reconhecidos como de ordem "cultural", como veremos logo adiante. Diante desta situação, poder-se-ia supor a existência de um certo sentimento de frustração, ou ao menos de tensão, entre a missão invertida que se propõe a reevangelizar a Europa e a que se torna "diaspórica", como ocorre, aliás, com as igrejas africanas na Europa ${ }^{33}$. Ora, tal não parece ser o caso das igrejas de Porto Alegre. Esta ambiguidade aparente não as desencoraja de enviar missionários para a Europa, nem os pastores de pregarem em cidades europeias. Podemos, então, sugerir que a missão invertida para a Europa possui outras significações para além do discurso estrito de "reevangelizar a Europa".

Com efeito, não se pode desprezar, por exemplo, o interesse econômico de certas igrejas e certos pregadores e missionários em desembarcar na Europa, o que não é incompatível com o trabalho missionário, inscrito na lógica da fluidez entre o religioso e o econômico. Veja-se, neste sentido, a declaração do pastor Valdeci, da Assembleia de Deus de Porto Alegre $^{34}$ : "Elas [as igrejas europeias] pagam muito bem aos que vão lá e pregam a palavra de Deus. Vale a pena". Neste caso, pode-se imaginar que o apoio financeiro dado aos missionários para chegarem à Europa, como vimos anteriormente, não deixa de constituir um investimento das igrejas devido ao retorno financeiro que elas podem vir a auferir com o trabalho efetuado por eles nas cidades europeias.

Um outro sentido ligado à missão invertida na Europa concerne a possibilidade aberta a sujeitos brasileiros e latino-americanos (pregadores, pastores, missionários, fiéis que nutrem o sentimento de se tornarem missionários), muitos deles pertencentes às camadas baixas e média-baixas da sociedade, de manterem contatos internacionais e se sentirem cidadãos do mundo, ligados a países tidos de Primeiro Mundo como os europeus. Assim, da mesma forma que historicamente o pentecostalismo permitiu a muitas pessoas o acesso à leitura, à política e às mídias, ele abre hoje aos seus membros os horizontes da Europa e do mundo. O pentecostalismo seria, assim, como sublinham Ruiz e Michel, "um dos espaços privilegiados de produção do global" (2012:15; tradução livre). 
Mas há ainda outro significado inscrito no imaginário da "missão invertida" para a Europa conduzida pelas igrejas de Porto Alegre, a saber: sua utilização enquanto recurso simbólico de legitimação num contexto religioso concorrencial "local".

De fato, como sabemos, as relações entre as centenas de igrejas evangélicas e pentecostais, independentemente do seu tamanho, são de concorrência, aberta ou velada, pela conquista das almas ${ }^{35}$. Ora, na atual conjuntura de abertura ao global, o investimento na circulação internacional pelos países europeus tornou-se um destino preferencial de líderes religiosos, para que eles e as igrejas adquiram junto à membresia em geral um plus de legitimidade. Isto se deve à imagem construída sobre a Europa neste e em outros meios religiosos, tida como moderna, berço do cristianismo e origem de muitos revivalismos religiosos.

Assim, as igrejas que enviam missionários para a Europa e os pastores que fazem pregações em cidades europeias nutrem um sentimento de elevação de status, e não somente junto aos seus fiéis. Isso se nota pela ênfase local dada aos fluxos missionários na Europa, que ganham espaço nos cultos e, especialmente, nos jornais e páginas virtuais das igrejas. Neste contexto, igrejas e pastores estão persuadidos a ganharem pontos nas disputas simbólicas e disputas de fiéis que mantêm com outros pastores e igrejas locais que não possuem parcerias globais. Sendo assim, este significado da missão invertida ajuda a compreender o não recuo do envio de missionários para a Europa, mesmo quando este exige altos custos por parte das igrejas locais.

Portanto, as igrejas pentecostais abrem-se para o "global" para se reforçarem no "local", para ganharem pontos aqui, diante da concorrência "local". Além da articulação entre o "local" e o "global", pode-se sugerir que exista, neste caso, uma certa instrumentalização do "global" pelo "local". Se esta análise está correta, podemos então traduzir a expressão nativa "conquistar espiritualmente a Europa" por "conquistar legitimidade local".

É importante sublinhar que esta mesma lógica que recorre à transnacionalização religiosa em direção da Europa como recurso simbólico de elevação de status num contexto religioso local concorrencial também ocorre com as demais igrejas pentecostais brasileiras que atuam no exterior, especialmente as megachurches neopentecostais. Porém, enquanto estas últimas tendem a valorizar e potencializar a sua condição de igrejas implantadas em "muitos" países de "todos" os continen- 
tes, as primeiras tendem a enfatizar a sua presença na Europa pelas razões apontadas anteriormente. Ambas, porém, acionam o imaginário da globalização como estratégia simbólica de reforço da legitimidade, visando, assim, elevar o seu prestígio e atrair mais fiéis locais.

Fica claro, portanto, que a missão invertida para a Europa realizada pelas igrejas locais utiliza as parcerias como estratégia para deslanchar a transnacionalização que, na realidade, cumpre sentidos múltiplos, entre os quais um anunciado - o de "recristianizar a Europa" - e outros não ditos (talvez subentendidos), como o interesse econômico, a abertura para o global e a elevação de prestígio no ambiente concorrencial local. Como em todas as situações semelhantes, são provavelmente estes últimos que impulsionam e garantem a energia da transnacionalização para a Europa. Outro aspecto associado à missão invertida diz respeito às tensões vividas pelos missionários brasileiros na Europa devido, segundo eles, às diferenças culturais, especialmente à importância que a emoção assume no pentecostalismo brasileiro e suas restrições neste meio religioso no continente europeu ${ }^{36}$.

\section{TENSÕES E CONFLITOS}

Os depoimentos dos brasileiros que possuem experiência missionária na Europa dão conta de que a sua ação pastoral às vezes se obstaculiza, chegando a gerar tensões e até conflitos em razão de choques resultantes das diferenças culturais. "As culturas são totalmente diferentes", afirmou o pastor Dilermando (Igreja Maanaim). Por isso mesmo, falando de si próprio quando esteve no País de Gales em 2009, afirma que “o choque cultural foi muito grande". E quanto à sua estadia na Romênia, em 2013, disse que "o choque cultural não foi um choque para mim; foi um susto terrível". Também o pastor Luiz Bazerque (Igreja Batista Brasa) destaca que apesar da sua igreja "estar fazendo um bom trabalho [na Inglaterra], a maior barreira continua sendo a cultura". Recordemos, com Roy Wagner (2010:34), que o choque cultural, ao mesmo tempo que torna visível a cultura, também mostra a inadequação da ideia do eu "contra o pano de fundo do seu novo ambiente".

Os pastores brasileiros estranham, inicialmente, a formalidade e o rigor que vigoram na Europa também no campo religioso. Assim, pastor Dilermando relata que no País de Gales, em 2009, em sua primeira pregação ouviu do intérprete a recomendação de que o culto iria das 19 às 20 horas, devendo finalizar pontualmente às 20 horas. Conta que esta- 
va pregando e às $19 \mathrm{~h} 57$ ouviu do intérprete o apelo: "Amém pastor, amém!". Porém, como não havia ainda finalizado a sua mensagem, continuou. Disso resultou, continua ele, que "eram oito e cinco e todo mundo estava indo embora". Não entende, arremata, como "aquelas pessoas se sujeitam ao tempo, mas não à palavra de Deus". O formalismo é tanto na Europa, continua Dilermando, que "agendam visitas até entre parentes". Esta "rudeza" dos europeus, segundo a sua apreciação, torna-os "menos sociáveis do que os brasileiros" e "repercute também no campo religioso".

A formalidade e o autocontrole que vigoram na Inglaterra são apontados por Luiz Bazerque como um elemento prejudicial à atração de jovens nas igrejas. É por isso, diz ele, que as igrejas inglesas são frequentadas majoritariamente por idosos. Porém, acrescenta que os pastores brasileiros, ao esbanjarem alegria, atraem os jovens "pela música, por esse jeito dos brasileiros serem".

Mas é a presença da emoção na prática ritual e litúrgica que põe o maior problema, tornando-se a mais importante fonte de tensões entre os agentes religiosos brasileiros e europeus. Segundo os missionários brasileiros, a emoção não é bem aceita pelas igrejas europeias. Assim, para Bazerque, "na Inglaterra não há pentecostalismo com barulho, como ocorre aqui. Na igreja inglesa não tem barulho". Também não há expressão pública da emoção. "Aqui no Brasil", continua o pastor, "nas igrejas as pessoas se abraçam, se beijam; os ingleses firmam o braço pra tu não chegar muito perto, né? Te seguram bem assim, para que tu não chegue". Também o pastor Isaias destaca que "lá [na Europa] a gente não vê pessoas chorando, batendo palmas, se abraçando como aqui no Brasil. Os europeus são muito frios", arremata. Por sua vez, o pastor Joel Lucas, da Assembleia de Deus, também destaca que "a ênfase na questão pentecostal (emocional, aduzimos nós), que os missionários imprimem na Europa, não é muito aceito lá, junto às igrejas tradicionais". Esta é, segundo ele, uma das razões que impedem a boa relação entre missionários brasileiros pentecostais e pastores de igrejas evangélicas locais, o que conduz, com o tempo, os primeiros a "acabarem abrindo um trabalho independente, vinculado aqui [ao Brasil]".

Sobre esses tópicos levantados, vejamos agora os argumentos de um pastor italiano, que fala a partir da perspectiva europeia. Segundo Ugo Sottile $^{37}$, na Europa os horários dos cultos precisam ser cumpridos à 
risca e não podem exceder a duas horas, diferentemente do Brasil, onde podem durar três horas ou mais. Isto porque, justifica:

Os italianos são muito organizados. Se precisam acordar cedo, vão dormir cedo. Isto não acontece com outros povos, entre os quais os brasileiros. Esta é uma mentalidade própria dos europeus. Então, durante a semana não se pode fazer cultos muito longos (...). O ritmo da vida aqui e lá é diferente. Por isso tem que haver uma adaptação.

Ainda segundo o pastor italiano, outro tópico que é motivo de desentendimentos entre brasileiros e europeus é o pedido de ofertas durante os cultos, algo recorrente no Brasil, mas que não é bem aceito na Itália. Afirma, neste sentido: "os italianos não estão assim tão dispostos a dar ofertas. Se diz: ofertem, ofertem, ofertem, não vai para a frente". Nota-se aqui um aspecto que é central no pentecostalismo brasileiro e latino-americano, mas que encontra resistências na Europa. Trata-se da Teologia da Prosperidade, que aproxima o religioso e o econômico, sacralizando de certa forma o mercado e os bens materiais, especialmente o dinheiro. Esta perspectiva não é bem acolhida no pentecostalismo europeu, no qual prevalece a mentalidade que tende a separar o religioso do econômico, assim como o religioso do político.

Ainda de acordo com Ugo Sottile, os italianos não concordam sobretudo com a ênfase posta na emoção, dominante no pentecostalismo brasileiro. Segundo a sua ótica, pregar a cura e os prodígios num país como a Itália, usando da emocionalidade, "não dá certo". "A adoração não agrada muito ao italiano, porque o cansa". Em sua perspectiva, haveria uma relação entre pobreza, emocionalidade e prodígios (curas, milagres), algo observável num país como o Brasil, mas não na Itália.

Como explicar a resistência europeia em aceitar o pentecostalismo emocional? Segundo o sociólogo italiano Giuseppe Trombetta (2013:23, tradução livre), esta dificuldade resulta, em primeiro lugar, de uma longa hegemonia das igrejas católica, protestante e ortodoxa, que produziram "um habitus que respeita em grande medida o modo pelo qual a religião é definida pelas elites religiosas", dotando as pessoas de categorias cognitivas capazes de permiti-las distinguir o que é religião do que é falsificação. Nesta perspectiva europeia, torna-se difícil aceitar a mistura entre corpo e espírito, fé e exaltação psíquica, liturgia e espetáculo, assim como a relação entre religião e trabalho, religião e saúde, religião e economia, religião e bem-estar psíquico, presentes no modo de ser religioso do pentecostalismo em geral. Em 
segundo, prossegue o autor, falta à Europa o esforço de "'reapropriar-se da própria história', que é uma das matrizes do sucesso pentecostal nos países ex-coloniais" (idem), ou seja, o desejo de recuperar, graças à religião, os traços culturais que os colonizadores subordinaram ou condenaram. No caso da Europa, ocorreu ao longo da história uma domesticação daqueles traços por parte das igrejas estabelecidas, contribuindo, desta forma, para o "preconceito etnocêntrico" que se observa neste continente em relação à reevangelização proposta pelas igrejas pentecostais de imigrantes (Carranza, 2013).

Como proceder diante deste quadro marcado pelas diferenças culturais e religiosas constatadas entre as práticas pentecostais conduzidas pelos brasileiros e pelos europeus? O pastor italiano é de opinião que os missionários brasileiros precisam respeitar as culturas locais, e não impor a sua própria cultura religiosa. Em suas palavras:

eles [os pastores brasileiros] não podem chegar na Itália ou em algum outro país europeu, que são antiquíssimos, históricos, e dizer "nós no Brasil, na América, fazemos desta maneira e vocês devem fazer da mesma forma". Isto porque cada um tem a sua própria mentalidade, sua própria organização, certo?

O pastor Luiz Bazerque (Igreja Batista Brasa) também defende a necessidade de adaptação dos pastores brasileiros à cultura europeia. Segundo ele, "tem que entrar no sistema do dono da casa... tem que respeitar as regras deles". Para tanto, sua igreja procura preparar os seus missionários, estimulando-os a frequentar a escola de missiologia, sobretudo a cadeira de missiologia intercultural, para "conhecerem o povo que se vai trabalhar, porque, por exemplo, por mais pentecostal e renovado que seja o inglês, a fleuma do inglês vai continuar e então vai ter problema".

Diferentemente das posições acima, o missionário gaúcho Locatelli, da Assembleia de Deus, sublinha a necessidade de haver uma adaptação cultural mútua, dos brasileiros e dos europeus. Diz ele:

os brasileiros precisam aprender com os europeus a colocar ordem nas coisas, porque lá tudo é organizado. Na Inglaterra tudo é cronometrado, tudo é organizado. Se diz que um culto termina às seis, tem que terminar às seis, entendeu? (...) Os europeus também precisam aprender com os brasileiros. A gente ensina lá o calor humano, a receptividade, a se interessar pelo próximo. Isso lá não existe, cada um é pra si e Deus 
por todos, entendeu? É uma cultura muito individualista. A gente ensina muito lá esse calor humano brasileiro, essa relação, essa amizade, o companheirismo, se interessar pelos problemas dos outros, entendeu? Eles ficam admirados, ficam admirados como a gente consegue ser assim, entendeu?.

Nota-se que os agentes religiosos de ambos os lados do Atlântico são detentores de uma visão essencialista das culturas nacionais. Representam os brasileiros como sendo portadores de entusiasmo, alegria, emoção, e os europeus como formais, impessoais, controlados e racionais ${ }^{38}$. Além disso, os agentes religiosos sugerem que a transnacionalização religiosa implica em acomodações e adaptações, em movimentos centrípeto e centrífugo, que desencadeiam uma retroalimentação mútua, como também destacaram Carranza e Mariz em seu estudo sobre a expansão da Canção Nova para fora do país, sobretudo para Portugal $(2013: 29)^{39}$.

\section{CONCLUSÃO}

Vimos, por um lado, que a celebração de parcerias com agentes e igrejas europeias constitui o recurso estratégico utilizado pelas igrejas de Porto Alegre para dar início à transnacionalização religiosa em direção à Europa, tendo na recristianização da mesma o principal mote desencadeador do processo. Porém, a eficácia desta iniciativa é reduzida, o que permite supor que há outras razões concomitantes para a missão invertida para a Europa, entre as quais o fator econômico, a abertura para o global e a elevação de prestígio num contexto sociorreligioso "local". Neste caso, destaca-se o imaginário do "global" e, mais particularmente, a grandiosidade da evangelização da Europa para se fortalecer no "local". Por outro lado, vimos que as parcerias podem ser prejudicadas e, às vezes, até mesmo sucumbir diante das tensões atribuídas às diferenças de códigos culturais, geralmente essencializados, existentes entre a dita "cultura brasileira" e a "cultura europeia", com repercussão no campo religioso.

Enfim, dois aspectos permanecem problemáticos nas relações transnacionais que envolvem o pentecostalismo rio-grandense - quiçá o brasileiro e o latino-americano - e o europeu. Em primeiro lugar, a questão dos diferentes campos sociais, percebidos como relacionados na mentalidade pentecostal do subcontinente americano e como autônomos no meio pentecostal europeu; e, em segundo, a questão da emoção, que se torna uma espécie de "nó górdio" ao qual os pentecostalismos dos 
dois lados do Atlântico veem-se atados, dada a importância que ela ocupa no pentecostalismo brasileiro e latino-americano e a resistência que encontra no europeu.

Os dados apresentados favorecem a compreensão de aspectos tidos por vezes laterais pelas teorias que consideram a globalização num longo alcance. Os encontros culturais proporcionados por um pentecostalismo que se deseja globalizado acabam por lançar organizações de pequena escala e sujeitos em dilemas provenientes desse encontro, explorados aqui sob a forma de tensões e conflitos. Neste artigo, nos ocupamos de movimentos tipicamente transnacionais, entre os quais revela-se crucial a questão da adaptação cultural, sendo a transnacionalização apenas uma das modalidades de deslocamento. Caberia, ainda, uma última reflexão sobre a capacidade interpretativa das classificações de movimentos dentro do processo de globalização aqui expostos.

Como todo movimento e toda emergência só são observáveis em relação a um referencial no espaço ou no tempo, os fluxos globais deveriam ser vistos sempre em relação a referenciais e a unidades de análise discerníveis. Uma igreja que se transnacionaliza por contatos pessoais possui estratégias de difusão da mensagem religiosa diferentes de uma megachurch que se internacionaliza, pois há aqui formas de organização social da produção simbólica distintas, embora a mensagem possa ser considerada semelhante. Isso não quer dizer que uma igreja internacionalizada não se transnacionalize em algum outro nível, dependendo da unidade de comparação. Um caso excelente para interpretação é o da Igreja Universal do Reino de Deus na França (Aubrée, 2003), a qual encontrou seu público-alvo entre comunidades africanas em diáspora, recrutando pastores africanos e absorvendo os códigos simbólicos acerca dos malefícios (bruxaria, feitiçaria). Assim, essa igreja internacional em sua organização se transnacionaliza em sua prática do sermão e de cura das almas dirigida a uma comunidade imigrante não brasileira. Há vezes em que o inverso acontece: um modelo organizacional se transnacionaliza sem que igreja alguma se desloque. Tome-se, como exemplo, a organização de igreja em células ou modelo celular originária das Assembleias de Deus da Coreia do Sul, reinterpretada na Colômbia e difundida na América Latina em tonalidades absolutamente variáveis e locais.

A sistematicidade em nossas formas de interpretação dos fluxos poderá levar, futuramente, a bases seguras para a comparação desses fenô- 
menos. Além disso, poderá tornar mais precisas as linhas de força relacionadas à dimensão cultural e geopolítica das relações internacionais (pensamos aqui na atuação do Brasil como país hegemônico econômica e culturalmente frente aos países pobres da América Latina e da África), trazendo um benefício aos intérpretes contemporâneos que não prescindem do nacionalismo metodológico característico dos estudos sobre globalização. Por ora, buscamos, através de duas formas de atenção (teórica e empírica), contribuir com os estudos sobre globalização e religião na contemporaneidade.

(Recebido para publicação em abril de 2014)

(Reapresentado em março de 2015)

(Aprovado para publicação em agosto de 2015) 


\section{NOTAS}

1. O sociólogo italiano Giuseppe Trombetta define a "evangelização de retorno" na mesma direção: "os missionários, provenientes de igrejas efervescentes nos países ex-coloniais, 'retornam' para evangelizar os descendentes dos seus evangelizadores agora secularizados, propondo um cristianismo alternativo ao exportado pelos missionários no tempo da colonização: uma religião intelectualizada, privada da energia vital que só a presença do Espírito pode dar" (2013:13; tradução livre).

2. Desde 2008 acompanhamos igrejas e organizações religiosas de Porto Alegre que enviam missionários para a Europa. Estas quatro igrejas foram escolhidas por manterem esse interesse de forma programática, organizada e constante.

3. O tema das parcerias e das redes também foi objeto de um livro de Joanildo Burity, fruto de uma longa pesquisa conduzida no Brasil. Nele, o autor analisa as organizações da sociedade civil - como instituições religiosas, entidades filantrópicas e organizações não governamentais - que operam em redes e parcerias na sua relação com o Estado e o mercado, visando contribuir na implantação de políticas sociais que ensejem sobretudo a promoção da cidadania e o combate à pobreza. Burity mostra como as redes e parcerias constituem-se em modelo de relação ou recurso estratégico para o alcance de objetivos comuns de parte das instituições implicadas, que, para tanto, acionam razões pragmáticas e substantivas (Burity, 2006). Neste texto, a análise vai se concentrar nas parcerias que ocorrem no interior do campo religioso transnacional entre igrejas e agentes religiosos brasileiros e europeus.

4. Faremos as seguintes considerações inspirados na recensão bibliográfica de Pries sobre o tema (2005), retrabalhada em artigo de Alves (2012).

5. Alguns autores, especialmente os ligados à tradição francesa de reflexão sobre o tema, preferem o termo mundialização para analisar este processo. Para o aprofundamento acerca das diferenças entre globalização e mundialização, ver, entre outros, as reflexões teóricas de Ortiz $(1994,2006)$ e de Capone $(2002,2004)$.

6. Recordamos que, segundo M. Abélès, o conceito de globalização é preferido nos meios anglo-saxônicos enquanto mundialização é mais utilizado entre os franceses, referindo-se a "uma aceleração dos fluxos de capital, de seres humanos, de mercadorias e de imagens e de ideias. Esta intensificação das interações e das interconexões produz relações que transcendem as fronteiras geográficas e políticas tradicionais" (2008:37-38; tradução livre). Seja como for, para o antropólogo francês a globalização possui uma dupla dimensão transfronteiriça, factual e imaginária.

7. A expressão rede de relações ou, mais diretamente, social networks, foi cunhada por Barnes, em 1954 (Mitchell, 1974). Nas décadas de 1950 e 1960 houve um verdadeiro boom na utilização desse conceito, que se tornou também um método. Em 1979, Jeremy Boissevain contabilizou mais de mil artigos até então publicados sobre o tema (Alves, 2008). O estudo sobre as redes sociais transnacionais começa nos anos 1970, oportunizado por uma série de conferências patrocinadas pela ONU sobre temas como meio ambiente, direitos das mulheres e direitos humanos, acompanhado do crescimento das ONGs em todo o mundo. Nos anos 1990, as redes transnacionais merecem maior atenção, impulsionadas pela Conferência Eco-92, ocorrida no Rio de Janeiro, a Conferência Mundial sobre a Mulher em Beijing, em 1995, e os protestos 
contra a Organização Mundial do Comércio (OMC) em Seattle, em 1999 (Barnes, Reilly e Pisani, 2007:63-92).

8. Para estes autores, transnacionalização é "toda relação que, por vontade deliberada ou por destinação, se constrói no espaço mundial além do quadro estatal nacional e que se realiza escapando ao menos parcialmente do controle ou da ação mediadora dos Estados" (Badie e Smouts, 1995:70; tradução livre).

9. Carlos Annacondia nasceu em 1944 e se converteu aos 35 anos de idade. Na década de 1980, investiu forte na evangelização da Argentina seguindo o modelo de pregação das "tendas itinerantes". Ao longo dos anos 1990, conduziu inúmeras campanhas de evangelização, não mais somente na Argentina, mas também em outros países latino-americanos e europeus, tornando-se um pregador bastante requisitado. Desde então, sua legitimidade carismática cresceu no cenário internacional (Wynarczk, 1993).

10. Segundo entrevista realizada por Daniel Alves, em 2010, então doutorando do Programa de Pós-Graduação em Antropologia Social da Universidade Federal do Rio Grande do Sul (PPGAS/UFRGS).

11. A Igreja Batista Brasa surgiu em Porto Alegre em 1986, como resultado de um processo de renovação ocorrido no interior da Primeira Igreja Batista Brasileira. Possui templos em várias cidades do sul do Brasil. Na Europa, possui três igrejas em Portugal e desenvolve trabalho missionário na Inglaterra há 15 anos. A maioria dos quase 60 missionários enviados para a Europa desde o final dos anos 1990 foi para o Reino Unido. Marcelo Guimarães foi o primeiro pastor dessa Igreja enviado para a Inglaterra. Mora em Bognor Regis, no sul do país. Está neste local há 13 anos e fez, inicialmente, parceria com a igreja Batista local. Mais tarde firmou parcerias com igrejas evangélicas de Bishop's Stortford e de Edinburgo. Atualmente em Porto Alegre, Luiz Bazerque é o responsável do setor missionário da Igreja.

12. Em entrevista que nos concedeu em $9 / 11 / 2011$.

13. Em entrevista concedida em $28 / 9 / 2011$. A Assembleia de Deus de Porto Alegre - filiada à Convenção Geral das Assembleias de Deus no Brasil - possui na atualidade aproximadamente 65 missionários atuando no exterior, dos quais cerca de 30 estão na Europa, sobretudo na Inglaterra e em Portugal. O pastor Joel Lucas é hoje o secretário de missões da Igreja em Porto Alegre.

14. A Igreja Maanaim foi fundada em Porto Alegre no ano 2000 por Josué Dilermando, que afirma ter tido aos 5 anos de idade um sonho-revelação no qual por detrás de um sol muito forte ouviu uma voz que dizia: "Josué, tu és meu filho. Eu tenho uma obra muito grande contigo. Eu te levarei para outras nações". Assim, considera que o seu ministério nasceu com vocação missionária transnacional. Pastor Dilermando já realizou três viagens missionárias para a Europa: em 2009 para o País de Gales; em 2012 para Roma e em setembro/ outubro de 2013 para Bucareste e Roma. Em fevereiro de 2011 enviou um casal de pastores da sua igreja para iniciar o trabalho missionário em Roma. São eles os pastores Edilson e Ana Avila. Partiram com os três filhos e lá se encontram até o momento.

15. Ugo Sottile é um italiano nascido em Messina que se converteu, juntamente com toda a sua família, aos 14 anos de idade. Em viagem realizada ao nordeste brasileiro, conheceu uma frequentadora da Assembleia de Deus, ministério de Madureira, com a qual se casou. No Rio de Janeiro conheceu o pastor Manuel Ferreira que o nomeou 


\section{Ari Pedro Oro e Daniel Alves}

seu procurador na Itália. Regularizou esta igreja na Itália e hoje está à frente de 32 igrejas espalhadas por todo o país. Sottile pastoreia numa igreja situada perto de Roma, em Tor Vergata, via Angelo Bianchi. Além disso, é presidente da Convenzione Nazionale delle Assemblee di Dio Ministero Madureira, diretor de uma instituição chamada Italyforchrist e tesoureiro da organização das Igrejas Cristãs Evangélicas na Itália.

16. Conforme entrevista concedida a Erico Tavares de Carvalho Júnior, estudante do curso de Ciências Sociais da UFRGS, em 14/10/2013.

17. Pastor Dilermando afirmou em seu Facebook, em 22 de setembro, que "nesta igreja o pastor foi preso e condenado a morte pelo ditador Nicolau Ceaucescu, no período da ditadura comunista".

18. Em entrevista realizada em 17/6/2011

19. De acordo com entrevista realizada em 24/4/2010. Isaías Figueiró fundou o Ministério Encontros de Fé em 1988, em Porto Alegre. Reúne atualmente cerca de 20.000 fiéis. Já viajou para Portugal, em 2008, para a Itália, em 2009, para a Suécia, em várias oportunidades, e para a Alemanha, em 2011.

20. Doravante as declarações dos personagens referidos resultam das entrevistas realizadas nas datas acima mencionadas.

21. Trata-se de um dos expoentes mundiais da música gospel, com mais de 60 LPs e CDs lançados em diferentes idiomas.

22. Em entrevista concedida em $24 / 11 / 2011$.

23. Para uma análise da importância desta e de outras tecnologias de comunicação nas expressões religiosas ver Machado (2007).

24. Em sua última viagem para a Europa, o pastor Dilermando postou no seu Facebook várias mensagens e troca de informações com seus fiéis e conhecidos antes, durante e após a viagem. Postou também vários pequenos vídeos de cerca de dois minutos que mostravam algumas atividades que realizou em Roma e em Bucareste, seja orando e pregando em templos, seja andando nas ruas e centros comerciais, seja conversando e comendo nos restaurantes e em casas de irmãos.

25. Trata-se de um casal de pastores da igreja Maanaim, fundada por Dilermando, que em maio de 2011 embarcou para Roma para ali atuar como missionários.

26. Em entrevista, concedida a Erico Tavares, aluno do curso de Ciências Sociais da UFRGS, em 14/10/2013.

27. Modernidade, como sabemos, é uma noção confusa, sendo ao mesmo tempo mito e realidade. Irradiou-se no Ocidente a partir da confluência do iluminismo francês e da aufklaerung alemã (Baudrillard, 1985), tornando-se uma meta a ser alcançada, um valor que todos reivindicam, um programa cultural que indivíduos e sociedades se propõem a cumprir e, finalmente, uma ideologia, ou seja, "a concepção de mundo que o homem 'moderno' de qualquer latitude vivendo nos novos tempos deve adotar" (Vaz, 1991:24). Como frisou Jean Séguy, a modernidade conhece patamares porque não atinge igualmente toda uma sociedade, podendo se contradizer e tomar formas diversas. O plural é a sua marca (Séguy, 1989).

28. Entrevista realizada em 17/6/2011. 
29. Atos 1:8 diz: “(...) mas descerá sobre vós o Espírito Santo e vos dará força; e sereis minhas testemunhas em Jerusalém, em toda a Judéia e Samaria e até os confins da terra".

30. Em entrevista concedida a Mariana Picolotto, então estudante de Ciências Sociais da UFRGS, em 20/10/2011.

31. Outros estudos conduzidos sobre este mesmo tema em outros contextos sociais assinalam a importância da língua utilizada nas igrejas seja para dificultar a aproximação de pessoas pertencentes a diferentes países seja para atrair os que dominam a mesma língua. Entretanto, as identidades nacionais e as composições étnicas não podem ser negligenciadas enquanto critérios de aproximação ou de repulsão social. Por exemplo, Pace e Butticci põem em relevo a barreira linguística e o etnocentrismo, e até mesmo o racismo italiano em relação às igrejas africanas na Itália, como sendo elementos que "criam uma distância social considerável" (2010:92; tradução livre). Daí porque, continuam os autores, "são ainda pouquíssimos os exemplos de Igrejas (africanas) que conseguiram atrair fiéis italianos" (idem).

32. Quando isto acontece, geralmente observa-se a existência prévia de uma relação afetiva (amizade, namoro, casamento) entre brasileiros pentecostais e europeus, que resulta no ingresso destes últimos no pentecostalismo.

33. De fato, Fourchard, Mary e Otayek (2005) sublinharam a existência de uma tensão que atinge as igrejas africanas que visam evangelizar a Europa e o mundo mas que acabam por se tornar, na Europa, refúgios identitários de migrantes. Seja como for, aparece aqui um importante papel desempenhado pelo pentecostalismo transnacionalizado. Como sublinham Pace e Butticci (2010), um processo migratório, que não é um processo diaspórico mas pode vir a sê-lo na medida em que houver uma redefinição das fronteiras identitárias e comunitárias. É aqui que o pentecostalismo cumpre um papel na produção do sujeito diaspórico, contribuindo para sua reconfiguração identitária num contexto migratório. Assim sendo, "num contexto social de forte isolamento, marginalidade econômica e racismo, tais Igrejas fornecem uma válida oportunidade para recompor e reescrever a identidade coletiva em novas comunidades definidas pelos confins do cristianismo" (ibidem:104; tradução livre).

34. Entrevistado por Mariana Picolotto, do curso de Ciências Sociais da UFRGS, em $3 / 11 / 2011$.

35. Além da competição por fiéis, uma outra competição importante ocorre entre as igrejas para atrair os chamados "levitas", isto é, os cantores, instrumentistas e dançarinos.

36. Esta mesma observação já havia sido feita por Paul Freston (2010:171).

37. Este pastor nos concedeu, gentilmente, duas entrevistas: uma em Porto Alegre, em 13/1/2011, e outra em Roma, em 17/10/2011.

38. Esta representação é recorrente. Cristina Rocha e Manuel Vásquez (2013a:7) observam, a respeito da diáspora religiosa brasileira pelo mundo, que circula "um imaginário global do Brasil, de sua cultura e religiões como exóticas, sexy, transgressoras, primitivas e autênticas, em contraste com a superficialidade, impessoalidade, monotonia e artificialidade da vida cotidiana nos países desenvolvidos".

39. Isto significa que se faz necessário no futuro pesquisar até que ponto as igrejas locais se retroalimentam com as experiências vividas pelos seus representantes nos países europeus, bem como as possíveis mudanças que atingem as igrejas europeias em razão da presença de missionários brasileiros e latino-americanos. 


\section{REFERÊNCIAS BIBLIOGRÁFICAS}

ABÉLÈS, Marc. (2008), Anthropologie de la Globalisation. Paris, Payot.

ALVES, Daniel. (2008), A Religião em Rede. Trabalho apresentado no XXXII Encontro Anual da Anpocs, Caxambu, 27-31 de outubro.

. (2011), Conectados pelo Espírito: Redes Pessoais de Contato e Influência entre Líderes Carismáticos e Pentecostais ao Sul da América Latina. Tese (Doutorado em Antropologia Social), PPGAS/UFRGS, Porto Alegre.

. (2012), “Aportes Teórico-metodológicos para o Estudo de Redes Transnacionais de Líderes Pentecostais e Carismáticos". Horizontes Antropológicos, vol. 18, no 37, pp. 45-71.

ARGYRIADIS, Kali et al. (orgs.). (2012), Religions Transnationales des Suds: Afrique, Europe, Amériques. Paris, L'Harmattan.

AUBRÉE, Marion. (2003), "A Igreja Universal na França”, in A. P. Oro; A. Corten; J.-P. Dozon (orgs.), Igreja Universal do Reino de Deus: Os Novos Conquistadores da Fé. São Paulo, Paulinas, pp. 189-198.

BADIE, Bertrand; SMOUTS, Marie-Claude. (1995), Le Retournement du Monde: Sociologie de la Scène Internationale. Paris, Presse de la Fondation Nationale des Sciences Politiques \& Dallorz.

BARNES, Nielan; REILLY, Katherine; PISANI, Francis. (2007), “Conceptuación de las Redes Transnacionales: Una Revisión de la Literatura Selecta", in F. Pisani et al. (orgs.), Redes Transnacionales en la Cuenca de los Huracanes. Un Aporte a los Estudios Intermericanos. México, Instituto Tecnológico Autónomo de México, pp. 63-92.

BASTIAN, Jean-Pierre; CHAMPION, Françoise; ROUSSELET, Kathy. (2001), La Globalization du Religieux. Paris, L1Harmattan.

BAUDRILLARD, Jean. (1985), "Modernité", in Encyclopaedia Universalis, vol. 12, Paris, pp. 424-426.

BURITY, Joanildo. (2006), Redes, Parcerias e Participação Religiosa nas Políticas Sociais no Brasil. Recife, Fundação Joaquim Nabuco/Editora Massangana.

CAPONE, Stefania. (2002), "Du Pareil au Même": Olhares Críticos da Antropologia Francesa sobre as Noções de Globalização, Transnacionalização e Postmodernismo. Trabalho apresentado na 23a Reunião Brasileira de Antropologia, Associação Brasileira de Antropologia, Gramado, 16-19 de junho.

. (2004), “À Propos des Notions de Globalisation et de Transnationalisation". Civilisations, vol. 51, pp. 9-22.

. (2010), “Religions en 'Migration': De l’Étude des Migrations Internationales à l'Approche Transnationale". Autrepart, vol. 56, pp. 235-259.

CAPONE, Stefania; MARY, André. (2012), “Les Translogiques d'une Globalisation Religieuse à l'Envers", in K. Argyriadis et al. (orgs.), Religions Transnationales des Suds. Paris, L'Harmattan, pp. 27-45. 


\section{Encontros Globais e Confrontos Culturais}

CARRANZA, Brenda. (2013), “Il Cristianesimo Pentecostale: Nuovo Volto della Chiesa Cattolica", in P. L. Trombetta (org.), Cristianesimi senza Frontiere: Le Chiese Pentecostali nel Mondo. Roma, Borla, pp. 73-92.

; MARIZ, Cecília. (2013), “Canção Nova: Catolicismo Tipo Exportação e Missão Reversa". IHU On-Line - Revista do Instituto Humanitas, no 424, pp. 27-31.

CASTELLS, Manuel. (2000), A Sociedade em Rede: A Era da Informação, Economia Sociedade e Cultura. (8a ed.). São Paulo, Paz e Terra.

CINGOLANI, Pietro; GUSMAN, Alessandro (orgs.). (2013), “La Sfida del Pentecostalismo". Erreffe - La Ricerca Folklorica, no 65.

FOURCHARD, Laurent; MARY, Andre; OTAYEK, René. (2005), Entreprises Religieuses Transnationales en Afrique de l'Ouest. Paris, Karthala.

FRESTON, Paul. (2004), “Les Dynamiques Missionaires Internationales du Pentecôtisme Brésilien", in S. Fath (org.), Le Protestantisme Évangélique: Un Christianisme de Conversion. Paris, Brepols, pp. 123-143 (Bibliothéque de l'École des Hautes Études Science Religieuses; 121).

. (2010), "Reverse Mission: A Discourse in Search of Reality?". PentecoStudies, vol. 9, no 2, pp. 153-174.

FRIGERIO, Alejandro. (1993), "'La Invasión de las Sectas': El Debate sobre Nuevos Movimientos Religiosos en los Medios de Comunicación en Argentina". Sociedad y Religion, no 10/11, pp. 32-69.

(2013), “A Transnacionalização como Fluxo Religioso na Fronteira e como Campo Social: Umbanda e Batuque na Argentina”. Debates do NER, no 23, pp. 15-57.

HANNERZ, Ulf. (1996), Transnational Connections. London, Routledge. Disponível em http:/ / www.ihuonline.unisinos.br/index.php?seção=424.

MACHADO, Maria das Dores Campos. (2007), “Globalización y Secularización". Cultura y Religion, vol. 1, pp. 108-125.

MARY, André. (2008), "Africanité et Christianité: Une Interaction Première". Archives de Sciences Sociales des Religions, no 143, pp. 9-31.

MITCHELL, Clyde. (1974), "Social Networks". Annual Review of Anthropology, vol. 3, pp. 279-299.

ORO, Ari Pedro. (2010), “'Reciben lo que Veniran a Buscar'. Nação e Poder num Encontro Evangélico Internacional, em Buenos Aires". Religião e Sociedade, vol. 30, no 1, pp. 32-52.

ORO, Ari Pedro; MOTTIER, Damien, (2012), “Entreprenariat Charismatique et Dynamiques Transatlantiques de Reconquête Spirituelle (Amérique du Sud/Afrique/Europe)", in K. Argyriadis et al. (orgs.), Religions Transnationales des Suds. Paris, L'Harmattan, pp. 193-212.

ORO, Ari Pedro; STEIL, Carlos Alberto; RICKLI, João (orgs.). (2012), Transnacionalização Religiosa: Fluxos e Redes. São Paulo, Terceiro Nome.

ORO, Ari Pedro et al. (orgs.). (2009), Debates do NER - Transnacionalização Religiosa, Porto Alegre, UFRGS.

ORTIZ, Renato. (1994), Mundialização e Cultura. São Paulo, Brasiliense.

DADOS - Revista de Ciências Sociais, Rio de Janeiro, vol. 58, nº 4, 2015 


\section{Ari Pedro Oro e Daniel Alves}

. (2006), Mundialização: Saberes e Crenças. São Paulo, Brasiliense.

PACE, Enzo; BUTTICCI, Annalisa. (2010), Le Religioni Pentecostali. Roma, Carocci.

PRIES, Ludger. (2005), "Configurations of Geographic and Societal Spaces: A Sociological Proposal between 'Methodological Nationalism' and the 'Spaces of Flows'”. Global Networks, vol. 5, no 2, pp. 167-190.

ROBERTSON, Roland. (1996), Globalização: Teoria Social e Cultura Global. Petrópolis, RJ, Vozes.

ROCHA, Cristina; VÁSQUEZ, Manuel. (2013), The Diaspora of Brazilian Religions. Leiden, Brill.

(2013a), "Sementes ao Vento: A Diáspora das Religiões Brasileiras no Mundo". IHU On-Line - Revista do Instituto Humanitas, no 424, pp. 6-8.

RUIZ, Jesús Garcia; MICHEL, Patrick. (2012), Et Dieu sous-traita le Salut au Marché. De l'Action des Mouvements Évangéliques en Amérique Latine. Paris, Armand-Colin.

SÉGUY, Jean. (1989), "Modernité Religieuse, Religion Métaphorique et Rationalité". Archives des Sciences Sociales des Religions, no 67/2, pp. 191-210.

SMITH, Michael; GUARNIZO, Luis E. (eds.). (1998), Transnationalism from Below. New Brunswick, Transaction Publisher.

SPINDLEER, Marc; LENOBLE-BART, Annie. (2000), Chrétiens d'outre-Mer en Europe. Un autre Visage de l'Immigration. Paris, Karthala.

TROMBETTA, Pino Lucà (org.). (2013), Cristianesimi senza Frontiere: Le Chiese Pentecostali nel Mondo. Roma, Borla.

VAZ, Henrique de Lima. (1991), "Além da Modernidade". Síntese Nova Fase, vol. 18, pp. $141-154$

WAGNER, Roy. (2010), A Invenção da Cultura. Rio de Janeiro, Cosac e Naify.

WÄHRISH-OBLAU, Claudia. (2008), The Missionary Self-Perception of Pentecostal/Charismatic Church Leaders from the Global South in Europe. Leiden, Brill.

WYNARCZK, Hilário. (1993), “Carlos Annacondia: Un Estudio de Caso en Neopentecostalismo", in A. Frigerio (org.), Nuevos Movimientos Religiosos y Ciencias Sociales (II). Buenos Aires, Centro Editor de América Latina, pp. 80-97. 


\section{RESUMO}

Encontros Globais e Confrontos Culturais: O Pentecostalismo Brasileiro à Conquista da Europa

O artigo analisa quatro igrejas pentecostais de Porto Alegre que põem em prática a política da "reconquista espiritual da Europa" posto que, segundo elas, este continente tornou-se demasiadamente materialista e estaria abandonando o cristianismo. Para atender este objetivo, o de "recristianizar a Europa", essas igrejas fecham acordos de parcerias com igrejas e agentes religiosos de países europeus como "recurso estratégico" para deslanchar a "missão invertida". Porém, como na Europa a maioria dos fiéis e dos missionários das igrejas de Porto Alegre não é composta por europeus, mas brasileiros, latinos e africanos, sugerimos que a "missão invertida" detém outros sentidos, para além do verbalizado, como auferir benefícios econômicos, abrir-se para o "global" e elevar o prestígio das igrejas e dos agentes no contexto sociorreligioso "local". Enfim, analisam-se as tensões vividas pelos missionários brasileiros na Europa devido aos choques culturais que enfrentam e que repercutem na prática religiosa, sobretudo em relação ao espaço reservado à emoção nos rituais.

Palavras-chave: pentecostalismo; transnacionalização religiosa; parceria religiosa; "missão invertida"; recristianização da Europa

\section{ABSTRACT}

Global Encounters and Cultural Confrontations: Brazilian Pentecostalism and Its Quest for Europe

This article analyzes four Pentecostal churches from Porto Alegre, Brazil, that are engaged in a "spiritual reconquering of Europe" based on a comprehension that the continent has become over materialistic and on the verge of abandoning Christianity. In order to understand this aim, that of "rechristianizing Europe," these churches forge agreements with churches and religious agents in Europe as a "strategic resource" to the effect of launching an "inverted mission". However, as in Europe most of the faithful and church missionaries from the Porto Alegre churches do not comprise Europeans but rather Brazilians, Latin Americans and Africans, we suggest that the "inverted mission" contains other meanings, beyond those articulated verbally, such as conferring monetary benefits, going "global" and elevating the prestige of churches and agents in the "local" socio-religious context. In sum, the article analyzes the tensions experienced by Brazilian missionaries in Europe due to the cultural shocks they face and the ripple through their religious practice, specially in relation to the spaces intended for emotion in rituals.

Keywords: Pentecostalism; religious transnationalization; religious partnerships; "inverted mission"; rechristianization of Europe 


\section{RÉSUMÉ}

Rencontres Globales et Chocs Culturels: Le Pentecôtisme Brésilien à la Conquête de l'Europe

Cet article a pour but d'étudier quatre églises pentecôtistes de Porto Alegre mettant en pratique une politique de "reconquête spirituelle de l'Europe", étant donné qu'elles estiment que ce continent est devenu trop matérialiste et qu'il délaisserait le christianisme. Pour atteindre cet objectif de "rechristianisation de l'Europe", ces églises concluent des accords avec des institutions et des agents religieux de pays européens dans le cadre d'une stratégie de mise en œuvre de cette "mission inversée". Néanmoins, sachant qu'en Europe la majorité des fidèles et des missionnaires des églises de Porto Alegre n'est pas composée d'Européens, mais plutôt de Brésiliens, de Latino-Américains et d'Africains, nous suggérons que cette "mission inversée" revêt d'autres significations allant au-delà du discours assumé, à savoir l'obtention de ressources économiques, l'ouverture au "global" et l'augmentation du prestige des églises et de leurs agents au sein du contexte socioreligieux "local". On analysera enfin les tensions vécues par les missionnaires brésiliens en Europe en raison des chocs culturels qu'ils subissent et qui se répercutent sur leur pratique religieuse, principalement en ce qui concerne la place réservée à l'émotion dans les rituels.

Mots-clés: pentecôtisme; internationalisation religieuse; partenariat religieux; "mission inversée"; rechristianisation de l'Europe

\section{RESUMEN}

\section{Encuentros Globales y Choques Culturales: El Pentecostalismo Brasileño a la Conquista de Europa}

Este artículo analiza cuatro iglesias pentecostales de Porto Alegre que ponen en marcha una política de "reconquista espiritual de Europa" dado que, según ellas, dicho continente se ha tornado demasiado materialistas y estaría abandonando el cristianismo. Para atender este objetivo de "recristianizar Europa", estas iglesias realizan acuerdos con iglesias y agentes religiosos de varios países europeos como "recuro estratégico" para proyectar una "misión invertida". Sin embargo, como en Europa la mayoría de los fieles y de los misioneros de las iglesias de Porto Alegre no son europeos, sino brasileños, latinos y africanos, sugerimos que esta "misión invertida" remite a otros sentidos, más allá de lo verbalizado, como la obtención de beneficios económicos, la apertura a lo "global" y el incremento del prestigio de las iglesias y de los agentes en el contexto socio-religioso "local". En definitiva, se analizan las tensiones vividas por los misioneros brasileños en Europa debido a choques culturales que enfrentan y que repercuten en la práctica religiosa, sobre todo en relación al espacio reservado a la emoción en los rituales.

Palabras clave: pentecostalismo; transnacionalización religiosa; acuerdos religiosos; "misión invertida"; recristianización de Europa 